I SUSTentabiLIDADE • PEQUENAS QUE Vão LONGE 


\section{PEQUENAS QUE VÃO LONGE}

\section{Os desafios globais da sustentabilidade estão moldando os negócios internacionais. Para algumas empresas, isso representa barreiras. Para outras, especialmente as micro e pequenas, pode ser fonte de grandes oportunidades.}

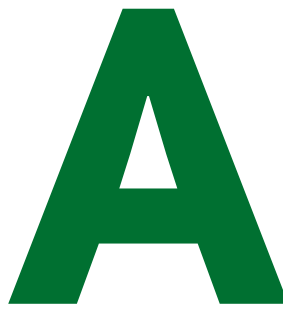

pesar dos recentes sinais de protecionismo e restrições comerciais, tanto em países desenvolvidos quanto em desenvolvimento, os mercados seguem cada vez mais conectados. Mudanças significativas são observadas não só no que é transacionado internacionalmente, mas também em como e por quem se dá essa comercialização. Embora as grandes corporações continuem dominando as estatísticas do comércio internacional, a novidade é a emergência das micro e pequenas empresas (MPEs), que revelam enorme potencial de se tornarem importantes atores na arena global de negócios.

Representando mais de $90 \%$ das empresas formalmente constituídas mundialmente, como revela o relatório MSME Country Indicators, da International Finance Corporation (IFC), as MPEs também são importantes empregadoras, mas isso ainda não lhes garante expressividade na balança de exportações.
No caso do Brasil, de acordo com o Ministério da Indústria, Comércio Exterior e Serviços (MDIC), as MPEs são responsáveis por mais de $50 \%$ dos empregos formais, apesar de o faturamento de suas exportações corresponder a apenas $0,8 \%$ do valor total exportado pelo país. No entanto, a pouca representatividade nas exportações pode mudar, como revela o mais recente relatório da Organização Mundial do Comércio (OMC), sob o título Levelling the trading field for SMEs.

\section{MPES: PROTAGONISTAS}

\section{DE SOLUÇÕES INOVADORAS}

Não que as MPEs ocuparão o lugar das grandes corporações no volume de exportações, mas percebe-se, especialmente nos países em desenvolvimento como o Brasil, que elas têm o potencial de diversificar as pautas tradicionais concentradas em grandes empresas fornecedoras de commodities, adicionando produtos e serviços com maior valor agregado. Daí surgem os desafios da sustentabilidade, em geral complexos e de escala global, como as novas fontes de oportunidade para 
as empresas que oferecem soluções a partir dos atributos de seus produtos, serviços ou modelos de negócio.

Mudança climática, perda de biodiversidade, desigualdade na distribuição de renda, precarização de direitos humanos e trabalhistas, entre outros desafios que compõem a agenda da sustentabilidade, deixam claro que nosso modelo de produção e consumo não é capaz de fazer frente à demanda por bem-estar de uma população crescente em um planeta com recursos finitos.

Assim, tornam-se determinantes as inovações que não se limitam a adicionar eficiência aos modos tradicionais de produção e consumo, mas sim as que, por serem disruptivas, promovem mudanças radicais no design de seus produtos, na utilização de matérias-primas, na organização do trabalho, no uso e na distribuição de produtos e serviços e, até mesmo, na reincorporação de resíduos aos processos produtivos. Inovações que promovam não apenas a redução dos impactos socioambientais negativos das empresas, mas também a ampliação dos efeitos positivos e regenerativos sobre os ecossistemas e a sociedade como um todo.

Por sua agilidade, disposição para assumir riscos e capacidade de antecipar tendências, as MPEs têm se mostrado protagonistas nessas inovações disruptivas, diferentemente das grandes corporações, que, por estarem mais condicionadas ao status quo e comprometidas com volumes expressivos de recursos alocados em modelos tradicionais, tendem a se limitar às inovações incrementais. São as características das MPEs que as habilitam a atender às demandas de clientes e consumidores em diferentes lugares do mundo, cujas decisões de compra e consumo refletem cada vez mais a influência de questões socioambientais. Por pressões regulatórias, fatores competitivos ou motivações éticas, a demanda de compradores internacionais por atributos de sustentabilidade é percebida como importante alavanca de negócios para países em desenvolvimento como o Brasil.

Essa tendência no comportamento dos compradores internacionais não passou despercebida para organizações comprometidas em promover as exportações no Brasil, entre elas a Agência Brasileira de Promoção de Exportações e Investimentos (Apex-Brasil), que, em parceria com o Centro de Estudos em Sustentabilidade (GVces) da Escola de Administração de Empresas de São Paulo da Fundação Getulio Vargas (FGV EAESP), conduz o Projeto Inovação e Sustentabilidade nas Cadeias Globais de Valor (ICV Global) desde 2014.

\section{PROJETO ICV GLOBAL}

Lançado no fim de 2013, o projeto ICV Global tem por objetivos:

- Fomentar as exportações de MPEs brasileiras que possuem atributos de inovação e sustentabilidade em seus produtos, serviços ou modelos de negócio;

- Posicionar cadeias de valor brasileiras no mercado internacional com base em seus diferenciais de sustentabilidade e inovação.

Para atingir esses objetivos, implementou-se um conjunto de etapas em ciclos de 18 meses, como pode-se ver na figura. Nos dois ciclos realizados, o projeto recebeu inscrição de 147 MPEs na etapa "Chamada de casos", das quais 40 foram selecionadas por um comitê de especialistas com base em critérios que avaliam o grau de inovação e sustentabilidade da empresa e de seus produtos e serviços.

Além da chamada de casos, convidam-se empresas de grande porte já internacionalizadas, que sejam âncoras de cadeias de valor e reconhecidas por suas práticas de sustentabilidade. Essas empresas, por sua vez, convidam seus parceiros comerciais estratégicos (fornecedores, distribuidores

\section{ETAPAS DO PROJETO INOVAÇÃO E SUSTENTABILIDADE EM CADEIAS GLOBAIS DE VALOR (ICV GLOBAL)}
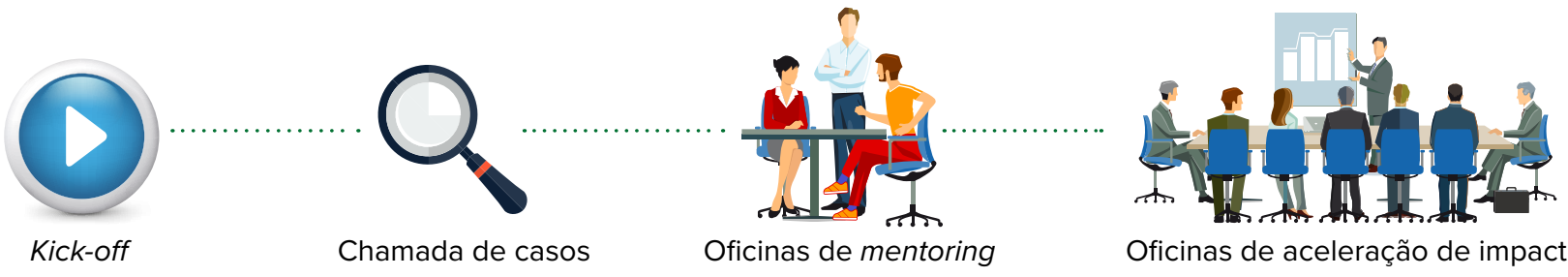

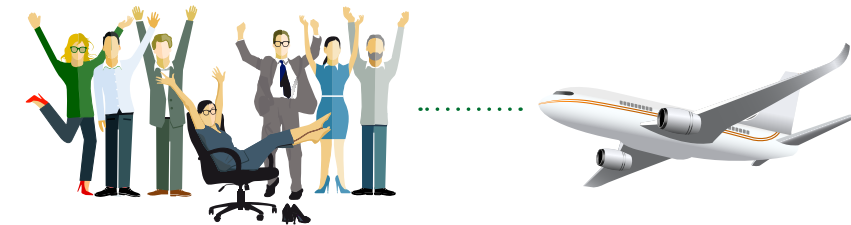

Ciclo de encerramento e planejamento
Promoção comercial

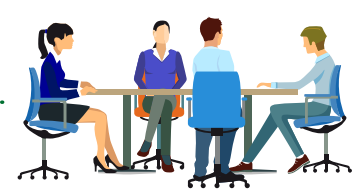

Rodadas de negócios 
e clientes), para garantir que os atributos socioambientais façam parte de toda a cadeia e criem diferenciais em mercados internacionais. Até agora já participaram quatro empresas âncora e 39 de seus parceiros comerciais.

Após a chamada de casos das MPEs e convite às âncoras e suas parceiras, tem início um intenso processo de coformação dos participantes em oficinas de mentoring e aceleração de impacto. Nessas oficinas, os atributos de inovação e sustentabilidade dos produtos e serviços das empresas são desenvolvidos e fortalecidos, assim como seu comportamento de mercado e seus argumentos de venda.

Finalizadas as etapas de mentoring e aceleração, o projeto oferece diferentes oportunidades às empresas visando à aproximação de mercados e potenciais compradores. $\mathrm{Na}$ etapa de promoção comercial, já houve missões com as MPEs para a Califórnia, nos Estados Unidos, além de Bogotá e Medellín, na Colômbia. Em todos os casos, buscou-se entender as características e os comportamentos dos respectivos mercados, assim como o ambiente de apoio ao empreendedorismo e à inovação. Nas rodadas de negócios, as empresas interagem com potenciais compradores internacionais dos mercados-alvo e com trading companies brasileiras que buscam produtos e serviços que se destacam pela inovação e pelo perfil sustentável.

Ao fim do ciclo, é lançada uma publicação com a descrição dos casos selecionados, as perspectivas de avanço

\begin{tabular}{|c|c|}
\hline EMPRESA & PERFIL \\
\hline Fornari & $\begin{array}{l}\text { Setor: Agronegócio } \\
\text { Fundação: } 2008 \\
\text { Funcionários: } 22 \\
\text { Clientes: BRF, JBS, Aurora Alimentos } \\
\text { Países importadores: Turquia, Filipinas, } \\
\text { Colômbia, Bolívia, Paraguai e Argentina }\end{array}$ \\
\hline Brasil Ozônio & $\begin{array}{l}\text { Setor: Química verde } \\
\text { Fundação: } 2004 \\
\text { Funcionários: } 13 \\
\text { Clientes: Bunge, Dow, Unilever, } \\
\text { Saneamento Básico do Estado de São } \\
\text { Paulo (Sabesp) } \\
\text { Países importadores: Argentina e Peru }\end{array}$ \\
\hline Safe Trace & $\begin{array}{l}\text { Setor: Agronegócio } \\
\text { Fundação: } 2005 \\
\text { Funcionários: } 12 \\
\text { Clientes: Carrefour, Walmart, Grupo Pão } \\
\text { de Açúcar, diversos frigoríficos } \\
\text { País importador: Chile }\end{array}$ \\
\hline
\end{tabular}

da agenda de sustentabilidade e comércio internacional, bem como os aprendizados.

\section{PEQUENAS EMPRESAS, GRANDES SOLUÇÕES}

Além dos resultados alcançados pelo ICV Global com as empresas participantes no que se refere ao desenvolvimento da cultura exportadora, ao aprimoramento de práticas de gestão e comércio exterior e à realização de negócios e exportações, é possível identificar o potencial de contribuição das MPEs para a solução dos desafios globais da sustentabilidade.

Um exemplo dos desafios ligados à segurança dos alimentos é a recente crise em 15 países da União Europeia, além de Suíça e Hong Kong, por causa da contaminação de ovos por um pesticida, levando à retirada de milhões de unidades do produto de supermercados alemães e holandeses. Esse caso soma-se a outros em mercados globais, como a Operação Carne Fraca, deflagrada no Brasil em março deste ano em razão de denúncias sobre adulteração de carnes por grandes empresas do setor e que ainda afeta as relações comerciais do país com seus compradores internacionais.

Entre as MPEs participantes do ICV Global, pode-se mencionar três cujos produtos e serviços propõem soluções inovadoras para desafios da segurança de alimentos em cadeias globais de valor, como mostra o quadro a seguir.

Sistema modular de baixo consumo de energia que, a partir do ar ambiente, produz ozônio para tratamento de água, ar e efluentes. Por suas funções bactericidas e oxidantes, o ozônio produzido tem aplicações como: eliminação de odores, sanitização de alimentos e combate a pragas na agricultura.

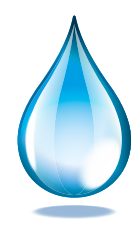

Monitoramento da cadeia produtiva de diversos produtos, que inclui carnes, frutas e legumes, de sua produção até o consumo. No caso da carne, as soluções de rastreabilidade garantem transparência desde a origem do alimento até sua exposição nas prateleiras

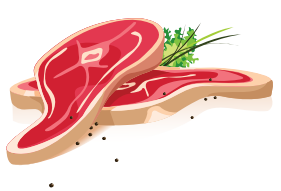


OPORTUNIDADES NO

\section{MERCADO INTERNACIONAL}

Apesar das dificuldades comuns às MPEs para a realização de negócios em mercados estrangeiros, como capacidade produtiva limitada, acesso restrito a crédito, barreiras logísticas, proteção de marcas e burocracias aduaneiras, há muitas oportunidades decorrentes do esforço de internacionalização e criação de uma cultura exportadora. Para as que já nasceram globais, conhecidas como born globals, ou que almejam mercados além-mar, algumas dicas podem ajudar a prosperar no comércio internacional com base em atributos de sustentabilidade e inovação.

\section{DICAS PARA MPES QUE BUSCAM OPORTUNIDADES NO COMÉRCIO INTERNACIONAL}

- Abordar a exportação como uma escolha estratégica, e não uma iniciativa pontual e vinculada apenas a vantagens cambiais;

- Fazer um diagnóstico consistente das práticas de sustentabilidade da sua empresa, assim como dos atributos dos seus produtos e serviços, seguido de um plano de ação realista para endereçar os pontos prioritários;

- Definir com clareza os mercados-alvo em que seus produtos e serviços terão mais chances de sucesso. Vale lembrar que "menos é mais" quando se trata da escolha dos países-alvo;

- Desenvolver um modelo de negócio adequado ao(s) mercado(s) escolhido(s), incluindo a proposta de valor para cada um, os canais de venda mais adequados, as atividades-chave que precisa $(\mathrm{m})$ desenvolver etc. Vale lembrar que o modelo de negócio que funciona no mercado interno nem sempre dá certo em mercados internacionais;

- Fazer os ajustes necessários em produtos, serviços e práticas de gestão para se adequar às exigências e expectativas dos mercados priorizados. Não esquecer de que embalagem e marca são itens-chave, assim como website e materiais de comunicação nos idiomas específicos;

- Fortalecer suas competências interculturais. 0 "portunhol" não é suficiente para construir relações duradouras com interlocutores de outros países. É importante entender como somos vistos pelos estrangeiros e como é a cultura de seus potenciais compradores;

- Buscar o apoio de organizações especializadas que poderão facilitar e encurtar a trajetória de sua empresa no comércio internacional. Entre as opções estão as associações setoriais, a Apex-Brasil, o Serviço Brasileiro de Apoio às Micro e Pequenas Empresas (Sebrae) e o projeto ICV Global.

\footnotetext{
PARA SABER MAIS:

Projeto ICV Global. Disponível em: icvglobal.com.br

Sérgio Adeodato, Ana Coelho e Paulo Durval. Do Brasil para o mundo: inovação e sustentabilidade nas cadeias globais de valor, 2017. Disponivel em: goo.gl/Tz5aQS

World Trade Organization. World Trade Report 2016: Levelling the trading field for SMEs, 2016. Disponivel em: https://www.wto.org/english/res_e/booksp_e/world_trade_report16_e.pdf

International Trade Centre (ITC). Disponivel em: goo.gl/sWv2W

Agência Brasileira de Promoção de Exportações e Investimentos (Apex-Brasil). Disponível em: goo.gl/VqaQ7D
}

PAULO DURVAL BRANCO > Vice-coordenador do GVces e professor da FGV EAESP > paulo.branco@fgv.br 